\title{
Nesse fascículo de ABCS Health Sciences
}

\section{In this issue of ABCS Health Sciences}

Ricardo Peres do Souto

Editor Responsável - ricardo.souto@ @mabc.br

DOI: http://dx.doi.org/10.7322/abcshs.v38i2.10

Neste fascículo de ABCS Health Sciences você poderá conferir:

- Oliveira e colaboradores (página 58) mostram a ocorrência de alterações estruturais nucleares em hepatócitos de animais de experimentação submetidos à privação de sono, somando-se a outras evidências recentes na literatura de uma grande variedade de efeitos biológicos desse fator estressor;

- Prado e colaboradores (página 63) encontram que o maior grau de comprometimento da função motora de crianças com paralisia cerebral avaliado está associado à menor qualidade de vida, conforme esperado. Desse modo, os autores alertam os cuidadores destas crianças que a reabilitação motora deve ter impacto positivo também na qualidade de vida de seus pacientes, hipótese que pode ser testada por outros estudos;

- Kubo e Nascimento (página 68) fazem um levantamento de experiências brasileiras de educação em asma no âmbito da atenção primária, promovendo um debate atual, considerando-se o presente contexto pedagógico da formação de profissionais de saúde, e de grande relevância para a elaboração de estratégias de redução do impacto da doença e de suas repercussões nos níveis secundário e terciário por controle inadequado;

- Souto e colaboradores (página 75) relatam uma avaliação epidemiológica e investigam em detalhes um surto pouco comum de infecções por Streptococcus pyogenes ocorrido em São Carlos (SP).

Ao final, a revista traz os Anais do 38 Congresso Médico Universitário do ABC (COMUABC)/1 Simpósio Internacional de Educação em Ciências da Saúde, a ser realizado na Faculdade de Medicina do ABC entre 12 e 17 de agosto de 2013. São 185 resumos incluindo o melhor da produção científica discente da instituição. 